\title{
Anomalous left main coronary artery origin, silent ischaemia, risk of sudden death: a triad detected by combining coronary CT and dipyridamole SPECT
}

\author{
Gian Piero Carboni, ${ }^{1}$ Pietro Sedati, ${ }^{2}$ Emidio De Marco ${ }^{2}$
}

1 Department of Nuclear Cardiology, Università Campus Bio-Medico, Rome, Italy ${ }^{2}$ Università Campus BioMedico di Roma, Roma, Italy

\section{Correspondence to} Professor Gian Piero Carboni, g.carboni@unicampus.it
To cite: Carboni GP, Sedati P, De Marco E. BMJ Case Rep Published online: [please include Day Month Year] doi:10.1136/bcr-2013200129

\section{DESCRIPTION}

In March 2013, a 72-year-old male patient presented with angina during strenuous effort (SE), a left bundle branch block, type 2 diabetes and hypertension. He was undergoing treatment with valsartan, metformin and aspirin. Dipyridamole infusion on thallium-201 single-photon emission cardiac tomography (SPECT) detected a septalinferior reversible defect (figure 1). Coronary tomography revealed the presence of an anomalous left main coronary artery (ALMCO) originating from the opposite sinus of Valsalva and coursing between the aorta $(\mathrm{AO})$ and the pulmonary artery (PA). The right coronary artery (RCA) arose at an acute angle from the same orifice of the ALMCO ${ }^{1}$ (figure 2). Coronary angiography confirmed the observation. The effort angina aetiology could be explained by the transient coronary blood flow reduction elicited by the systolic compression of the ALMCO that is produced by the AO and PA during SE. Sudden death is often the first manifestation of ALMCO. ${ }^{2}$ In this patient, the aortic root dilation may have compressed the acute angle take off of the RCA, inducing a dynamic stenosis. ${ }^{3}$

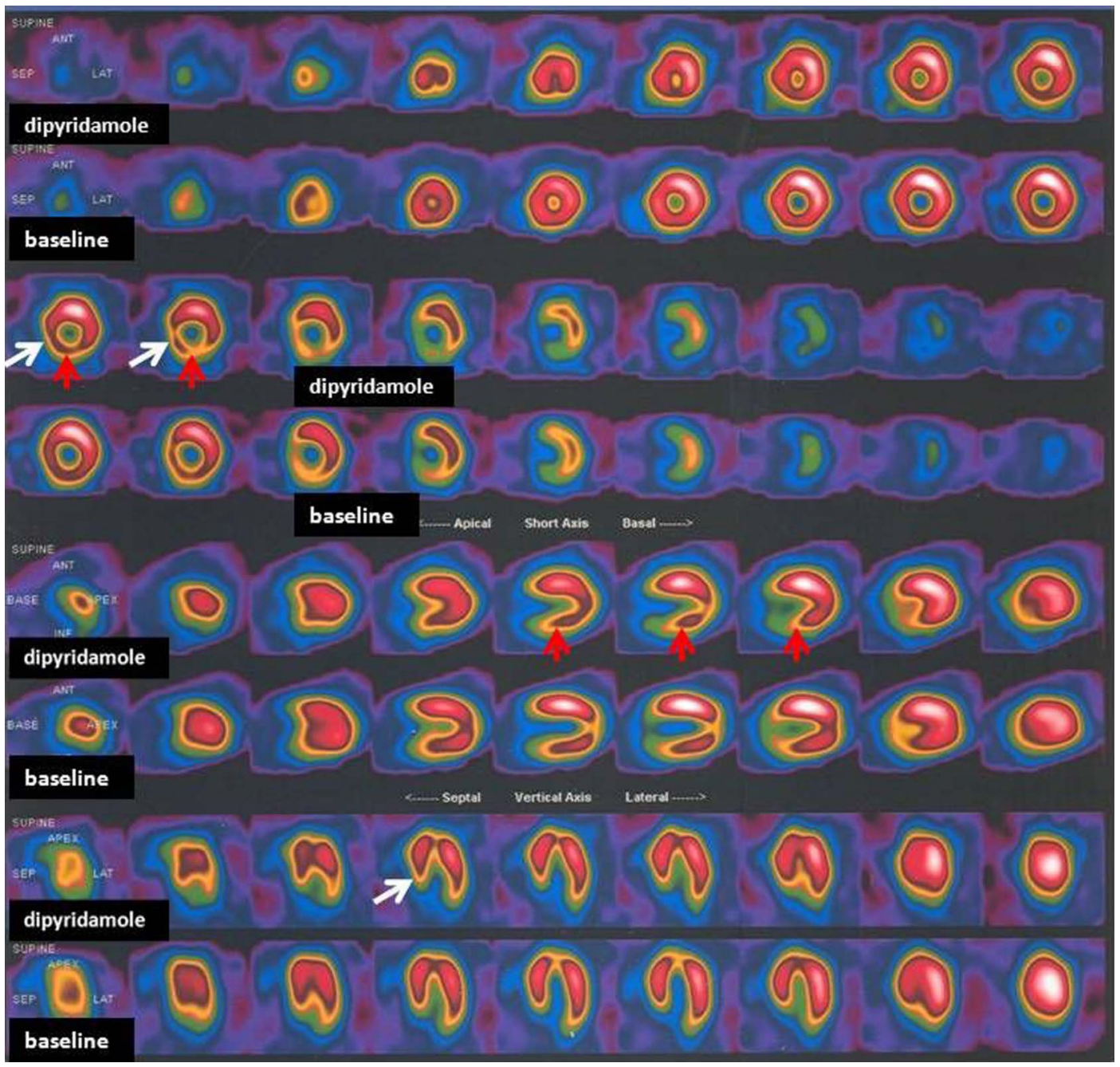

Figure 1 Pharmacological stress on thallium-201 single-photon emission cardiac tomography: mild, painless, reversible perfusion defects, inferior (red arrows) and septal (white arrows). The double product, measured after dipyridamole infusion, did not change from baseline values. 


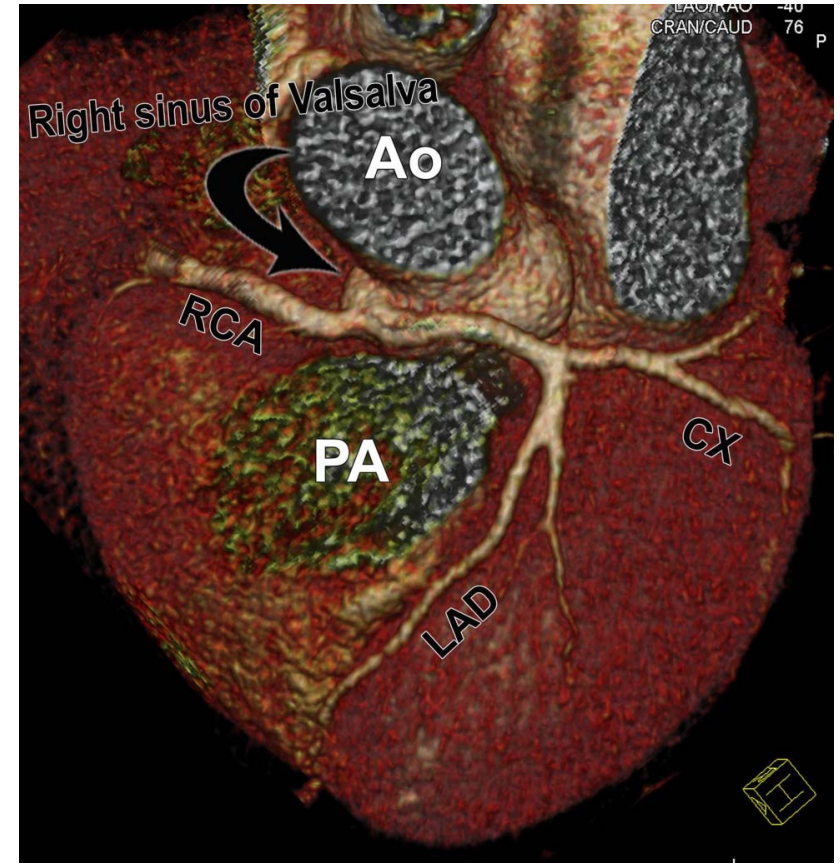

Figure 2 Volume-rendered cardiac CT images indicate extramural anomalies of the left main coronary artery originating from the opposite sinus of Valsalva and coursing between the aorta and the pulmonary artery. The right coronary artery arises with an acute angle from the same orifice of the left main coronary artery. Ao, Aorta; CX, circumflex artery; LAD, left coronary artery; PA, pulmonary artery; RCA, right coronary artery.

Perfusion may have then become dependent on collaterals. Thus, dipyridamole-induced flow steal from RCA collaterals could not be ruled out for the genesis of the septal-inferior wall ischaemia. ${ }^{4}$ In ALMCO, the decision for surgery must be balanced between the risk of sudden death decreasing with age, the presence of symptoms and the ischaemic territory involved. ${ }^{5}$ As ischaemia was mild and asymptomatic, we decided to increase the patient's myocardial protection with $\beta$-blockers and set up a simple annual surveillance.

\section{Learning points}

- Cardiac sudden death (CSD) mostly occurs in young men with anomalous left main coronary artery (ALMCO) during strenuous effort.

- A systematic screening for the risk of CSD should be undertaken in all patients with ALMCO.

- Combined coronary tomography and stress single-photon emission cardiac tomography may detect patients at high risk for CSD and suggest optimal therapeutic decisions.

- Treatment with $\beta$-blockers or dihydropyridine calcium-channel blockers may provide cardioprotection from inducible myocardial ischaemia.

- Surgical evaluation with reimplantation of the coronary arteries into their proper sinuses or with a saphenous vein or arterial coronary artery bypass graft is justified if myocardial ischaemia is detected. However, the optimal surgical technique is not yet defined.

Contributors GPC wrote the munuscript, PS and ED analysed the CT images and revised the manuscript.

Competing interests None.

Patient consent Obtained.

Provenance and peer review Not commissioned; externally peer reviewed.

\section{REFERENCES}

1 Opolski MP, Pregowski J, Kruk M, et al. Prevalence and characteristics of coronary anomalies originating from the opposite sinus of Valsalva in 8,522 patients referred for coronary computed tomography angiography. Am J Cardiol 2013;111:1361-7.

2 Jo $Y$, Uranaka $Y$, Iwaki $H$, et al. Sudden cardiac arrest: associated with anomalous origin of the right coronary artery from the left main coronary artery. Tex Heart Inst $J$ 2011;38:539-43.

3 Virmani R, Chun PK, Goldstein RE, et al. Acute takeoffs of the coronary arteries along the aortic wall and congenital coronary ostial valve-like ridges: association with sudden death. J Am Coll Cardiol 1984;3:766-71.

4 Fam WM, McGregor M. Effect of coronary vasodilator drugs on retrograde flow in areas of chronic myocardial ischemia. Circ Res 1964:15:355-64.

5 Warnes CA, Williams RG, Bashore TM, et al. ACC/AHA 2008 Guidelines for the management of adults with congenital heart disease: executive summary: a report of the American College of Cardiology/American Heart Association Task Force on Practice Guidelines (writing committee to develop guidelines for the management of adults with congenital heart disease). Circulation 2008;118:2395-451.

Copyright 2013 BMJ Publishing Group. All rights reserved. For permission to reuse any of this content visit

http://group.bmj.com/group/rights-licensing/permissions.

BMJ Case Report Fellows may re-use this article for personal use and teaching without any further permission.

Become a Fellow of BMJ Case Reports today and you can:

- Submit as many cases as you like

- Enjoy fast sympathetic peer review and rapid publication of accepted articles

- Access all the published articles

- Re-use any of the published material for personal use and teaching without further permission

For information on Institutional Fellowships contact consortiasales@bmjgroup.com

Visit casereports.bmj.com for more articles like this and to become a Fellow 